have been drawn up with the view of giving as much accurate information as is at present available on the subject of the total area of forests ; total volume of standing timber and increment; output of homegrown woods and of imports and exports for pre-war years, and each of the war years; and the effect of the war-time exploitation on forest capital and the future increment.

Owing to the very heavy war fellings made in countries both within the British Empire and outside, it is probable that accurate figures will not be available for some time to come. Moreover, in many of the forests under the Colonial Office, which are tropical forests containing numbers of different species of tree, very little is yet known about the actual volume present of commercially utilizable timber, and many of them have had to bear heavy war fellings in the accessible parts.

A most interesting paper was prepared by $\mathbf{M r}$. Lyle F. Watt, chief of the Forest Service, United States Department of Agriculture, entitled "The Forest Situation in the United States". Reports were made on the steps taken to carry out the resolutions of the 1935 Conference. These resolutions were nine in number, and for the information available the summary report should be consulted.

Technical committees were appointed as follows: (a) Land Use ; (b) Forest Management, Sylviculture and Protection; (c) Forest Products Research; $(d)$ Survey and Resources; (e) Education; (f) Timber Supply.

Various resolutions were drawn up by these different committees and submitted to the main Conference at its final meeting on July 19. The next Conference will take place in 1952, either in India or Canada.

\section{MAGNETIC FIELD OF MASSIVE ROTATING BODIES}

$I^{\mathrm{T}}$ may be permissible to add a footnote to the much-discussed article by Blackett ${ }^{1}$, in which he examines the proportionality. which seems to exist between the magnetic moment and angular momentum of massive rotating bodies such as the earth, sun and stars. He suggested that this simple result must have some profound physical significance, but that it seemed very probable that a satisfactory explanation would not be found except within the structure of a unified field theory. The purpose of this note is to direct attention to the claim of Prof. J. Mariani, of the Princeton Institute of Advanced Study, to have provided such an explanation and such a unified field theory. Mariani's more accessible publications appeared in C.R. Acad. Sci. Paris, 206, $1247(1938) ; 211,430(1940) ; 218,447$ and 585 $(1944)$; and "Electromagnétisme et relativité" (Cahiers de Physique Théorique, Paris, 1945), Part 1. However, the present summary has been prepared from his latest work, "Théorie des champs macroscopiques"', and a communication submitted to Nature for publication among "Letters to the Editors".

Mariani's latest treatment starts from philosophic considerations, akin to those of Kant, concerning the impossibility of knowing 'the thing in itself'. From the point of view of the average physicist, this is unfortunate. Even if he has the patience to read it, he may merely draw the depressing conclusion that no objective scientific measurement can exist. Thp next section of the work is something like a generalized theory of relativity, but with many coefficients that are quite indeterminate. Then suddenly, by means of a principle of identification, the treatment becomes much more definite. All the equations, except one, reduce to something like the ordinary gravitational theory of relativity. The one exception is the distinctive point of the theory, and its significance seems to be that a gravitational field must necessarily be accompanied by an electrical field.

The application of the theory to massive rotating bodies then proceeds very much on the lines of Sutherland, whose work is discussed in Blackett's article. The earth is supposed to have a positive volume charge compensated by a negative surface charge. This gives the desired proportionality between magnetic moment and angular momentum. The constant of proportionality is worked out for the earth, the sun, and the milky way, and shown to be of the right order of magnitude. It is also shown that for a copper sphere of radius $10 \mathrm{~cm}$. making 200 revolutions per second, the magnetic field is too small to be observed. This agrees with the experiment of Swann and Longacre, also discussed by Blackett.

Those who are interested in the matter will wish to examine Mariani's arguments for themselves; they will probably find the four short papers in Comptes Rendus easier to understand than the fuller and more philosophic version.

H. T. H. Piaggio

${ }^{1}$ Blackett, Nature, 159, 658 (1947).

Théorie des champs macroscopiques. Par Jean Mariani. Pp. ii +98 . (Paris : Centre de Documentation universitaire, 1947.) n.p.

\section{RECENT SOCIOLOGICAL PERIODICALS}

A PART from the specialized field of economics, A Britain has, until recently, suffered from a lack of journals devoted to the social sciences. The deficiency is now being made up by a variety of periodicals. Pilot Papers, as their subtitle of "Social Essays and Documents" suggests, usually take a wide sweep; but the number for June 1947 is devoted largely to American sociology. It contains a detailed review, by Dr. E. A. Shils, of recent American contributions to urban sociology, class stratification and race, family and small group problems, for which all students must be profoundly grateful. There is also an admirable study of the American child by $\mathrm{Mr}$. Gorer, stressing the dictatorship of such factors as the 'scientific feeding schedule' and the fear of being thought a 'sissy'.

American-type sociology is distinguished by using induction from collections of observed fact rather than philosophical deduction. Its methods are thus more akin to those of the natural sciences than the methods of the sociology and economics mainly pursued in Europe. The facts observed may be opinions and attitudes, and one welcomes the first volume of the International Journal of Opinion and Attitude Research, edited by Prof. Radvany, of the University of Mexico, with contributions from $H$. D. Lasswell, Henry Link and Tom Harrisson. The facts observed may also be the behaviour of human beings one to another, and to study behaviour as well as attitudes, a new journal, Anglo-American rather than fully international, is being launched under the title of Human Relations. The first number contains an 